\title{
Biocontrol of Avocado Dematophora Root Rot by Antagonistic Pseudomonas fluorescens PCL1606 Correlates With the Production of 2-Hexyl 5-Propyl Resorcinol
}

\author{
Francisco M. Cazorla, ${ }^{1}$ Simon B. Duckett, ${ }^{2}$ Ed T. Bergström, ${ }^{2}$ Sadaf Noreen, ${ }^{3}$ Roeland Odijk, ${ }^{1}$ \\ Ben J.J. Lugtenberg, ${ }^{1}$ Jane E. Thomas-Oates, ${ }^{3,2}$ and Guido V. Bloemberg ${ }^{1}$ \\ ${ }^{1}$ Leiden University, Institute of Biology Leiden, Clusius Laboratory, Wassenaarseweg 64, 2333 AL Leiden, The Netherlands; \\ ${ }^{2}$ Department of Chemistry, University of York, Heslington, York, YO10 5DD, U.K.; ${ }^{3}$ Michael Barber Centre for Mass \\ Spectrometry, Department of Chemistry, UMIST, Sackville Street, Manchester M60 1QD, U.K.
}

Submitted 29 June 2005. Accepted 6 November 2005.

A collection of 905 bacterial isolates from the rhizospheres of healthy avocado trees was obtained and screened for antagonistic activity against Dematophora necatrix, the cause of avocado Dematophora root rot (also called white root rot). A set of eight strains was selected on the basis of growth inhibitory activity against $D$. necatrix and several other important soilborne phytopathogenic fungi. After typing of these strains, they were classified as belonging to Pseudomonas chlororaphis, Pseudomonas fluorescens, and Pseudomonas putida. The eight antagonistic Pseudomonas spp. were analyzed for their secretion of hydrogen cyanide, hydrolytic enzymes, and antifungal metabolites. $P$. chlororaphis strains produced the antibiotic phenazine-1-carboxylic acid and phenazine-1-carboxamide. Upon testing the biocontrol ability of these strains in a newly developed avocado- $D$. necatrix test system and in a tomato- $F$. oxysporum test system, it became apparent that $P$. fluorescens PCL1606 exhibited the highest biocontrol ability. The major antifungal activity produced by strain $P$. fluorescens PCL1606 did not correspond to any of the major classes of antifungal antibiotics produced by Pseudomonas biocontrol strains. This compound was purified and subsequently identified as 2-hexyl 5-propyl resorcinol (HPR). To study the role of HPR in biocontrol activity, two Tn5 mutants of $P$. fluorescens PCL1606 impaired in antagonistic activity were selected. These mutants were shown to impair HRP production and showed a decrease in biocontrol activity. As far as we know, this is the first report of a Pseudomonas biocontrol strain that produces HPR in which the production of this compound correlates with its biocontrol activity.

Additional keywords: Persea americana.

Corresponding author: F. M. Cazorla; Fax: +34-952-132000; Telephone: +34-952-137587; E-mail: cazorla@uma.es

Current address for F. M. Cazorla: Departamento de Microbiología, Facultad de Ciencias, Universidad de Málaga, Campus Universitario de Teatinos, s/n, 29071-Málaga, Spain

Nucleotide sequence data reported are available in the GenBank database under accession numbers DQ073039 for 16S rDNA, DQ073040 and DQ073041 for the interrupted gene in mutant PCL1613 and DQ073042 and DQ073043 for the mutant PCL1614.
Avocado (Persea americana Mill.) is a crop plant that was relatively recently introduced into Europe. European avocado orchards are mainly located in Spain and Portugal, where root fungal diseases have proved to be the major threat to plant health.

Dematophora necatrix (teleomorph: Rosellinia necatrix), the agent that causes Dematophora root rot in avocado and in many other crops (this disease is also called white root rot), has a very wide host-range, including 170 plant species or varieties in 63 genera and 30 families of dicotyledonous angiosperms. This fungal pathogen is destructive to many fruit tree crops, including tropical and subtropical species such as avocado and mango (Mangifera indica L.), which are particularly susceptible (Sztejnberg and Madar 1980).

Disease development in avocado trees infected by $D$. necatrix is usually rapid, killing the trees within a few weeks of the first foliar symptoms. The pathogen is capable of surviving for many years and remaining active for long periods on residues of crops susceptible to D. necatrix, such as olive (Olea europaea L.), grapevine (Vitis vinifera L.), and almond (Prunus amygdalus Batsch.) that are common in the region. The high susceptibility of cv. Topa-Topa, the rootstock most frequently used in avocado orchards in this area, may have favored the increase in disease incidence (López-Herrera et al. 1998).

Control of avocado Dematophora root rot poses difficulties, because any preplanting treatment must have a long-term effect and any postplanting treatment must not adversely affect the crop (Sztejnberg et al. 1987). Several approaches have been used over the past two decades for the control of $D$. necatrix before planting, such as i) soil fumigation using methyl bromide (Sztejnberg et al. 1983), ii) soil solarization (LópezHerrera et al. 1998), which may induce disease suppressive activity of the soil by increasing microbial activities, resulting in protection of the plants (Greenberger et al. 1987), and iii) biological control using the antagonistic fungus Trichoderma harzianum (Sztejnberg et al. 1987). The use of bacterial strains as biocontrol agents against avocado soilborne phytopathogens has not been reported. Biological control of avocado diseases has not been investigated, although recently, an approach for isolating bacterial biocontrol strains for the control of avocado root rot caused by Phytophthora cinnamomi was reported (Yin et al. 2004).

Microbial mechanisms by which rhizobacteria may protect plants against soilborne pathogens include competition for 
niches (Paulitz 2000), antibiosis (O'Sullivan and O'Gara 1992), and the induction of systemic resistance (Pieterse et al. 1996). In recent years, several plant root-colonizing Pseudomonas spp. have been shown to be potent microbiological control agents in various plant-pathogen systems. The use of such plant growth-promoting rhizobacteria is considered an addition to and an alternative for chemical pesticides, several of which are a threat to our health and environment (de Weger et al. 1995; Lugtenberg et al. 1994).

Antifungal compounds produced by Pseudomonas spp. biocontrol agents that are correlated with biological effectiveness include phenazine-1-carboxylic acid (PCA) (Thomashow and Weller 1988), phenazine-1-carboxamide (PCN) (Chin-AWoeng et al. 1998), 2,4-diacetylphloroglucinol (DAPG) (Keel et al. 1992), pyrrolnitrin (PRN) (Howell and Stipanovic 1979), pyoluteorin (PLT) (Howell and Stipanovic 1980), hydrogen cyanide (HCN) (Voisard et al. 1989), siderophores (Becker and Cook 1988), and some hydrolytic enzymes such as proteases (Sacherer et al. 1994).

In this sense, Pseudomonas spp. produce many other antifungal substances (Budzikiewicz 1993), and many of them have not yet been related to the biocontrol activity of the microorganisms. This is the case with the antimicrobial activity of alkylresorcinol and especially the antifungal compound 2hexyl 5-propyl resorcinol (HPR), which is produced by Pseudomonas spp. (Kanda et al. 1975; Kitahara and Kanda 1975; Nowak-Thompson et al. 2003.)

In this paper, we report the screening of rhizosphere bacteria isolated from healthy avocado for in vitro antagonistic activity towards the fungal phytopathogen $D$. necatrix as well as against several other soilborne phytopathogenic fungi. The strongest antagonistic isolates against fungi belonged to the genus Pseudomonas and appeared to be able to suppress Dematophora root rot substantially in a novel avocado-Dematophora in vitro biocontrol test system, using plants from germinated avocado embryos. In addition, the strains were also active against tomato foot and root rot caused by Fusarium oxysporum f. sp. radicis-lycopersici. The antifungal metabolite produced by the best protective strain, P. fluorescens PCL1606, was structurally identified after purification, and its role in biocontrol was analyzed.

\section{RESULTS}

\section{Identification and antagonistic activity of selected rhizobacterial isolates.}

The numbers of culturable bacterial cells present on the avocado root samples were estimated after isolation and growth on tryptic soy agar (TSA) and King's B (KB) agar (King et al 1954) plates. The values for total culturable bacteria ranged from 5.3 to $6.5 \mathrm{log}$ CFU per gram of fresh weight avocado roots. In all root samples, the presence of pseudomonads was indicated by growth of colonies on PI (Pseudomonas isolation) medium and ranged from 2.8 to $4.5 \log$ CFU per gram of fresh weight of roots.

A total of 905 bacterial isolates were selected, based on abundance and differences in colony morphology, and were tested for their antagonistic ability against highly virulent Dematophora necatrix 400, using an agar plate assay. Antagonistic strains were isolated from all root samples, types of soil, and on all media used for isolation. The total percentage of antagonistic bacterial strains growing on TSA or KB agar plates, or both, was $8.7 \%$ (62 antagonistic bacterial isolates from 712 tested), most of which were fluorescent on $\mathrm{KB}$ medium, whereas the percentage of antagonistic Pseudomonas-like strains isolated from colonies growing on PI medium was $57.5 \%$ (111 antagonistic isolates from 193 tested). The antagonistic strains were subsequently tested against other soilborne fungi phytopathogenic to avocado and other plants, resulting in eight Pseudomonas-like isolates with broad antagonistic activity (Table 1).

Identification of these rhizobacterial isolates was performed by the API20NE and BIOLOG tests, combined with homology analyses of nucleotide sequences of polymerase chain reaction

Table 1. Identification and in vitro antagonistic ability of the selected strains from avocado rhizosphere against plant pathogenic fungi

\begin{tabular}{|c|c|c|c|c|c|c|c|}
\hline \multirow[b]{2}{*}{$\begin{array}{l}\text { Bacterial } \\
\text { strain }\end{array}$} & \multirow[b]{2}{*}{ Characterization } & \multicolumn{6}{|c|}{ Antagonistic activity on King's B agar plates against ${ }^{a}$} \\
\hline & & $\begin{array}{c}\text { Dematophora } \\
\text { necatrix }(n=5)^{\mathrm{b}}\end{array}$ & $\begin{array}{c}\text { Phytophthora } \\
\text { cinnamomi }(n=3)^{\mathrm{c}}\end{array}$ & $\begin{array}{l}\text { Rhizoctonia } \\
\text { solani }\end{array}$ & $\begin{array}{l}\text { Pythium } \\
\text { ultimum }\end{array}$ & $\begin{array}{l}\text { Sclerotium } \\
\text { rolfsii }\end{array}$ & $\begin{array}{c}\text { Fusarium oxysporum f. sp. } \\
\text { radicis-lycopersici }\end{array}$ \\
\hline PCL1601 & P. chlororaphis & ++ & ++ & $(+)$ & $(+)$ & ++ & ++ \\
\hline PCL1602 & P.fluorescens & + & + & - & - & + & $(+)$ \\
\hline PCL1603 & P. putida & ++ & + & + & $(+)$ & + & $(+)$ \\
\hline PCL1604 & P. chlororaphis & ++ & ++ & + & + & + & ++ \\
\hline PCL1606 & P.fluorescens & ++ & ++ & ++ & ++ & ++ & ++ \\
\hline PCL1607 & P. chlororaphis & ++ & $(+)$ & ++ & + & ++ & ++ \\
\hline PCL1609 & P. putida & + & + & + & - & + & - \\
\hline PCL1611 & P. chlororaphis & ++ & ++ & ++ & + & ++ & ++ \\
\hline
\end{tabular}

${ }^{\mathrm{a}}++=$ diameter of the growth inhibition zone $>10 \mathrm{~mm} ;+=$ diameter of the growth inhibition zone between 3 to 10 mm; $(+)=$ diameter of the growth inhibition zone $<3 \mathrm{~mm}$; and $-=$ no antifungal activity observed.

${ }^{\mathrm{b}}$ Five strains of Dematophora necatrix (400, 397, 358, CECT2817, and CECT2818, respectively), were tested and gave all similar results.

c Three strains of Phytophthora cinnamomi (344, 301, and 273, respectively) were tested and gave similar results.

Table 2. Production of hydrolytic activities and antifungal metabolites by the isolated Dematophora antagonistic bacterial strains

\begin{tabular}{|c|c|c|c|c|c|c|c|c|}
\hline \multirow[b]{2}{*}{ Production of } & \multicolumn{8}{|c|}{ Strains $^{\mathbf{a}}$} \\
\hline & PCL 1601 & PCL 1602 & PCL 1603 & PCL 1604 & PCL 1606 & PCL 1607 & PCL 1609 & PCL 1611 \\
\hline Protease & + & + & + & + & + & + & + & + \\
\hline Lipase & + & - & - & + & + & + & - & + \\
\hline$\beta$-Glucanase & - & - & - & - & - & - & - & - \\
\hline Cellulase & - & - & - & - & - & - & - & - \\
\hline $\mathrm{HCN}$ & + & $(+)$ & $(+)$ & + & - & + & $(+)$ & + \\
\hline Antifungal metabolite ${ }^{\mathrm{b}}$ & PCA, PCN & - & - & PCA, PCN & HPR & PCA, PCN & - & $\mathrm{PCA}, \mathrm{PCN}$ \\
\hline
\end{tabular}

a $-=$ absence; $+=$ presence; $(*)=$ very weak detection; NT $=$ no tested.

${ }^{\mathrm{b}} \mathrm{PCA}=$ phenazine-1-carboxilic acid, PCN = phenazine-1-carboxamide, and HPR = 2-hexyl 5-propyl resorcinol. 
(PCR)-amplified 16S rDNA fragments. These studies revealed that the selected rhizobacterial strains belong to the species Pseudomonas chlororaphis, $P$. fluorescens, and P. putida (Table 1).

P. fluorescens PCL1606 and the four strains of P. chlororaphis (PCL1601, PCL1604, PCL1607, and PCL1611) showed the strongest antagonistic activity against nearly all the fungi tested (Table 1). None of the rhizobacterial isolates showed clear antifungal activity against the pathogen Verticillium dahliae (data not shown).

The sequence of the 16S DNA of PCL1606, the strain on which further studies focused, was submitted to the GenBank database under accession number DQ073039.

\section{Preliminary analysis of antifungal activities produced by the isolated \\ Dematophora-antagonistic Pseudomonas spp. strains.}

The eight selected antagonistic strains were tested for the production of exoenzymatic activities (Table 2). All the rhizobacterial strains selected produced proteases. Lipase activity was produced by all $P$. chlororaphis strains and by $P$. fluorescens PCL1606. No $\beta$-glucanase or cellulase activities were detected as produced by the Pseudomonas strains. Strong HCN production was detected for $P$. chlororaphis strains, whereas very weak production was detected for $P$. fluorescens PCL1602 and $P$. putida strains PCL1603 and PCL1609 (Table 2).

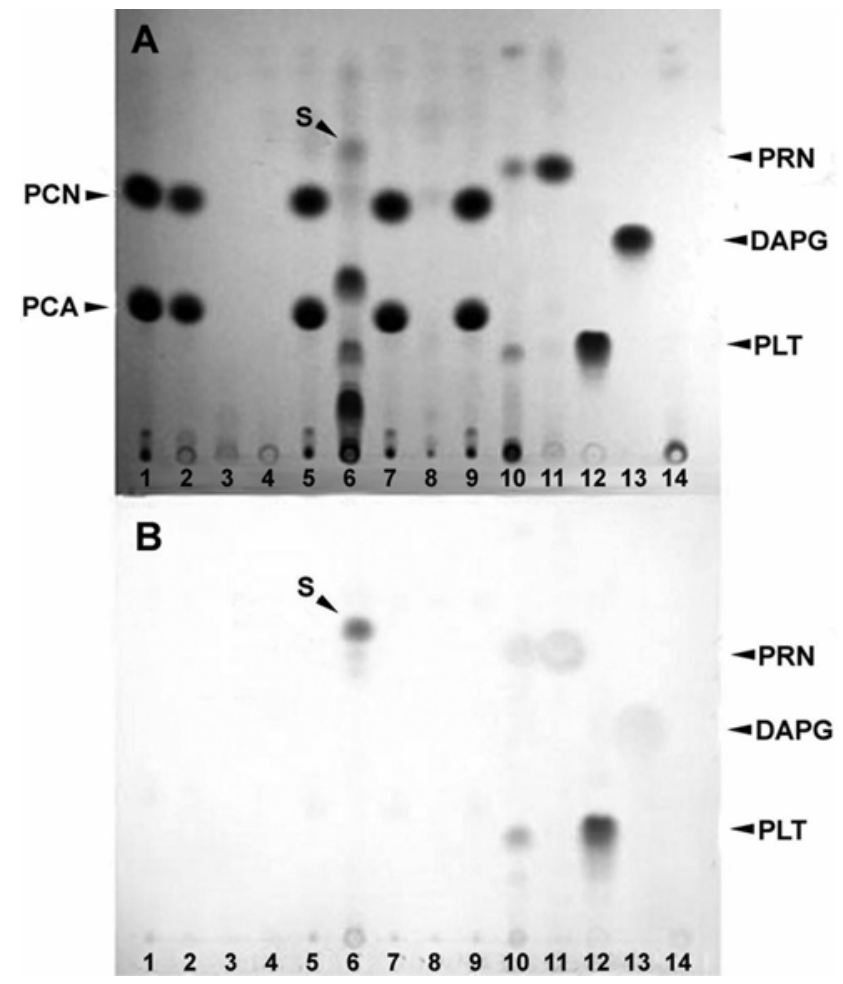

Fig. 1. Silica thin-layer chromatography analysis of organic solvent extracts of cell-free culture supernatants of Pseudomonas strains from the rhizosphere of avocado. Compounds were visualized $\mathbf{A}$, under ultraviolet light of $254 \mathrm{~nm}$ and $\mathbf{B}$, under visible light after spraying with diazotized sulfanilic acid. Lane 1: P. chlororaphis PCL1391; lane 2: P. chlororaphis PCL1601; lane 3: P. fluorescens PCL1602; lane 4: P. putida PCL1603; lane 5: P. chlororaphis PCL1604; lane 6: P. fluorescens PCL1606; lane 7: $P$. chlororaphis PCL1607; lane 8: P. putida PCL1609; lane 9: P. chlororaphis PCL1611; lane 10: P. fluorescens Pf5; lanes 11 through 13 contain standards of pyrrolnitrin (PRN, lane 11), pyoluteorin (PLT, lane 12), and 2, 4-diacetylphloroglucinol (DAPG, lane 13); lane 14: P. fluorescens WCS365. The spot "S" corresponds to an unidentified antifungal compound, with an $R f$ value of 0.86 , which is different from the $R f$ values of the major families of antifungal compounds and which was identified as described in this paper as 2-hexyl 5propyl resorcinol.
For preliminary identification of antibiotics with antifungal properties, different extractions with organic solvents were carried out from cell-free supernatants of KB liquid cultures of the eight selected strains. Extracts were separated using silica thin-layer chromatography (TLC), and the purified antifungal compounds, PCA and PCN, PRN, PLT, and DAPG were used as standards for comparison. All $P$. chlororaphis strains and the control strain P. chlororaphis PCL1391 (Chin-A-Woeng et al. $1998)$ produced compounds with the same $R_{f}$ values as PCA $\left(R_{f}=0.45\right)$ and PCN $\left(R_{f}=0.78\right)$. After observation under UV light and development of the TLC with diazotized sulfanilic acid (DASA), no compounds with similar $R_{f}$ values to PRN, PLT, and DAPG were detected for any of the Pseudomonas spp. strains tested, and only the control strain P. fluorescens Pf5 produced PRN and PLT as well as very small amounts of DAPG. No TLC spots were detected in the extracts of $P$. fluorescens PCL1602 or P. putida PCL1603 and PCL1609 or the control strain P. fluorescens WCS365 (Fig. 1) (Simons et al. 1996). Strain P. fluorescens PCL1606 showed different spots under ultraviolet light, but only one of these was very reactive with DASA (Fig. 1, indicated with "S"). This spot with $R_{f}=$ 0.86 was the only spot able to inhibit the growth of $D$. necatrix 400 in plate tests after extraction of all detectable spots from TLC plates. In addition, this spot inhibited the growth of $F$. $o x$ ysporum in a TLC bioassay.

\section{Biocontrol ability of the isolated Pseudomonas strains.}

Based on the method of germination of avocado embryos (Pliego-Alfaro et al. 1987), sufficient numbers of avocado seedlings with very well-developed root systems were obtained, which showed homogeneous characteristics in biocontrol experiments. These avocado seedlings were used to develop a novel avocado-Dematophora biocontrol test system using growth substrates infected with $D$. necatrix.

The isolates P. chlororaphis PCL1601 and PCL1611 and P. fluorescens PCL1606, which formed the largest growth-inhibition zone (Table 1), appeared to possess the best biocontrol activity in the avocado-Dematophora necatrix test system when vermiculite was used as inert substrate (Fig. 2A). In these tests, the previously isolated PCN-producing $P$. chlororaphis PCL1391 and the presumed inducer of systemic resistance $P$. fluorescens WCS365 were included as additional strains. Of the isolated antagonistic strains, P. fluorescens PCL1606 and P. chlororaphis PCL1601 caused the largest reduction in the number of diseased plants. Reduction in the number of diseased plants was correlated with a large reduction in disease severity. When no bacteria were applied to the avocado roots, the plants growing in vermiculite infected with $D$. necatrix showed a disease index of $74 \%$, whereas bacterization with the wild-type biocontrol strains $P$. chlororaphis PCL1601 and $P$. fluorescens PCL1606 reduced the disease indexes of the plants to 37 and 44\%, respectively (Fig. 2A). Application of the bacterial strains in substrate without added pathogenic fungi did not result in disease or any other visible response of the plant (data not shown).

When potting soil was used as a complex substrate in the biocontrol experiments, with the avocado-Dematophora system using the same strains and procedures, similar results were obtained (Fig. 2B) but the disease levels were slightly lower than when vermiculite was used $(66 \%$ diseased plants when no test bacteria were applied). Again, strains P. fluorescens PCL1606 and $P$. chlororaphis PCL1601 were the most protective strains against Dematophora root rot of avocado in potting soil (22 and 29\% disease index, respectively). The control strains $P$. chlororaphis PCL1391 and P. fluorescens WCS365 also showed biocontrol activity in this system, resulting in disease incidences of 40 and $39 \%$, respectively. 
The selected rhizobacterial strains were also tested in a tomato-F. oxysporum f. sp. radicis-lycopersici biocontrol system (Fig. 3). When no bacteria were applied to the tomato seeds, more than $75 \%$ of the plants were diseased after 16 days of growth in soil infested with $F$. oxysporum, whereas coating with cells of the most protective strains in this test system, $P$. chlororaphis PCL1601 and P. fluorescens PCL1606, reduced disease incidence to 30 and $26 \%$, respectively (Fig. 3). Other strains also significantly reduced the disease symptoms, with nearly all the Pseudomonas strains showing disease indexes below $60 \%$ and being significantly different from the uninoculated control (Fig. 3).

\section{Structural analysis of the antifungal compound produced} by $P$. fluorescens PCL1606.

To structurally identify the antifungal metabolite produced by $P$. fluorescens PCL1606, KB medium of a 4-day culture supernatant was extracted with chloroform/methanol (9:1). Antifungal activity of the spot migrating on TLC with an $R_{f}$ value of 0.86 was extracted and tested for activity in the $D$. necatrix microtiter plate bioassay and by the $F$. oxysporum TLC bioassay. Subsequently, the activity was purified by high-performance liquid chromatography (HPLC) analysis, showing that the activity eluted from the HPLC column after $31 \mathrm{~min}$ as a single

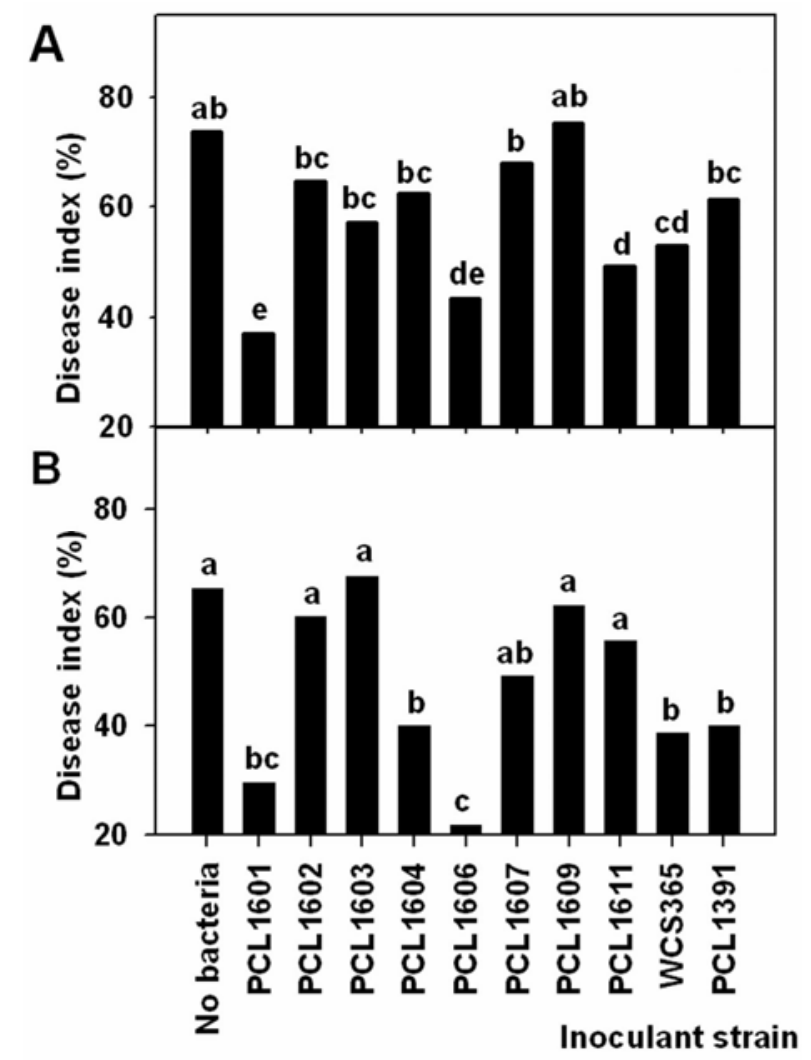

Fig. 2. Biocontrol of Dematophora root rot in avocado caused by Dematophora necatrix (teleomorph Rosellinia necatrix) by Pseudomonas strains isolated from the avocado rhizosphere. Eight strains isolated from the avocado rhizosphere as well as the previously described tomato foot and root rot biocontrol strains $P$. fluorescens WCS365 and P. chlororaphis PCL1391 were tested in a $D$. necatrix-avocado test system $\mathbf{A}$, in vermiculite and $\mathbf{B}$, in potting soil. Roots of avocado seedlings were inoculated with the different strains before transferring them to the different growth substances infested with $D$. necatrix. Plants were scored as sick or healthy after 18 to 21 days of growth after bacterization. Data were analyzed for significance after arcsine square root transformation with analysis of variance, followed by Fisher's least significant difference test $(P=0.05)$. Values of bars with different letter indications denote a statistically significant difference. peak (data not shown). In total, $10 \mathrm{mg}$ of the antifungal compound was purified and used for structural analyses.

Accurate mass measurement of the HPLC-purified antifungal component of PCL1606, obtained using electron ionization on a magnetic sector mass spectrometer gave an $\mathrm{m} / \mathrm{z}$ of 236.177, suggesting $\mathrm{C}_{15} \mathrm{H}_{24} \mathrm{O}_{2}$ as the most likely elemental composition; this has a double-bond equivalence of 4 . Nuclear magnetic resonance (NMR) studies suggested the structure to be 2-hexyl-5-propylbenzene-1,3-diol (also referred to as HPR) (Table 3). The mass spectrometric data collected on this sample support this assignment (Fig. 4).

${ }^{1} \mathrm{H}-\mathrm{NMR}$ spectra of the purified HPLC fraction eluting at 31 min (Fig. 4) at $700 \mathrm{MHz}$ produced eight resolvable features, which were then attributed to discrete carbon resonances via appropriate heteronuclear multiple quantum coherence (HMQC) spectra (Table 3). Notably, double quantum-filtered chemical shift-correlated spectroscopy measurements revealed the unambiguous presence of a propyl group in the isolated fraction (protons $\mathrm{k}, 1$, and $\mathrm{m}$ ). The unique singlet of area 2 at $\delta$ 6.05 suggested the presence of a pair of equivalent aromatic protons $\left({ }^{13} \mathrm{C}\right.$ for $\mathrm{CH}$ at $\left.\delta 107\right)$ with both long- and short-range HMQC measurements confirming the presence of three further carbon signals at $\delta 141, \delta 156$, and $\delta 113$ in this C6-based ring; none of the other carbons contained directly bound protons.

Examination of the proton spectrum (Table 2) revealed a triplet at $\delta 2.53$ for a group that was adjacent to the ring carbon resonating at $\delta 113$. This group forms part of a second ring substituent. A total of 11 proton resonances remained unaccounted for in the proton spectrum at this stage. A simple distorsionless enhancement by polarization transfer experiment located the associated carbon resonances as four separate $\mathrm{CH}_{2}$ signals at $\delta 22.8, \delta 29.4, \delta 29.6$, and $\delta 32.1$ with a $\mathrm{CH}_{3}$ signal at $\delta 13.2$. These proved to be characteristic of a hexyl group bound directly to the aromatic ring. These NMR spectra also contained an $\mathrm{OH}$ resonance at around $\delta 4.8$ that disappeared on shaking with $\mathrm{D}_{2} \mathrm{O}$, suggesting that the product is the simple symmetrical diol 2-hexyl-5-propylbenzene1,3-diol (Table 2).

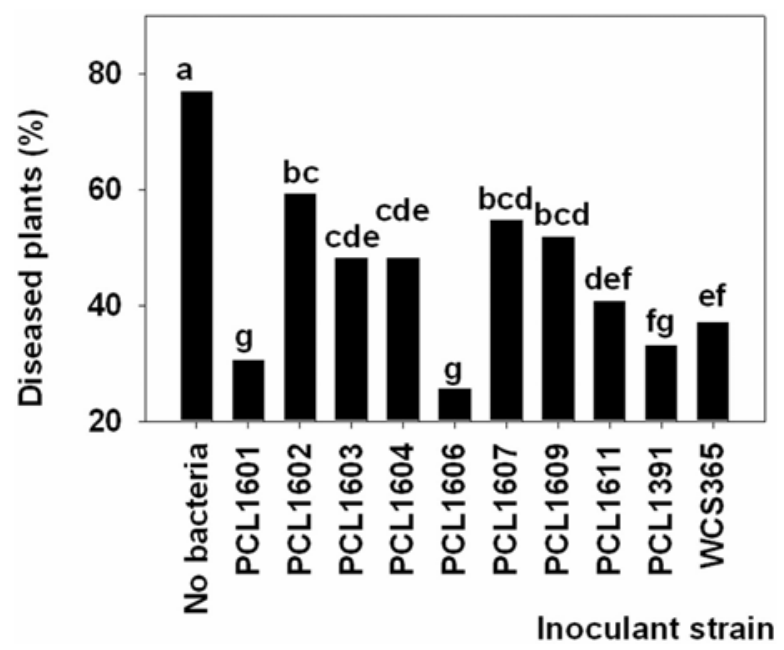

Fig. 3. Biocontrol of tomato foot and root rot caused by Fusarium oxysporum f. sp. radicis-lycopersici. Eight Pseudomonas strains isolated from the avocado rhizosphere as well as the biocontrol strains $P$. fluorescens WCS365 and $P$. chlororaphis PCL1391 were tested in a F. oxysporum-tomato test system using potting soil. Bacteria were coated onto tomato seeds prior to sowing in soil infested with Fusarium spores. Plants were scored as healthy or sick after 21 days of growth. Data were analyzed for significance after arcsine square root transformation with analysis of variance, followed by Fisher's least significant difference test $(P=0.05)$. Values of bars with different letter indications represent a statistically significant difference. 
Gas chromatographic-mass spectrometry (GC-MS) analysis of the component eluting at $31 \mathrm{~min}$ showed a single major peak. The very simple electron ionization mass spectrum of the component giving rise to that peak contained a signal for the $\mathrm{M}^{+}$ion at $\mathrm{m} / z, 236$ and only one major fragment ion at $\mathrm{m} / \mathrm{z} 165$ (data not shown). This would be consistent with the loss of $\mathrm{C}_{5} \mathrm{H}_{11}$ leaving a highly stable fragment ion with four resonance structures.

Electrospray ionization collision-induced dissociation tandem mass spectra $\left(\mathrm{MS}^{1}\right)$ were collected using an ion trap mass spectrometer. In positive ion mode, the $\mathrm{MH}^{+}$ion $\mathrm{m} / z 237$ was isolated and fragmented in the trap, to give three major fragment ions $(\mathrm{m} / \mathrm{z}, 195,153$, and 111) that can be assigned to the loss of either or both of the alkyl side chains (Fig. 4). Spraying the sample from deuterated solvent showed peaks in the mass spectrum at $m / z, 237,238,239$, and 240, suggesting the presence of two exchangeable protons plus the chargebearing species. Isolation and fragmentation of the $m / z, 240$ ion gave supporting evidence for this interpretation. Similarly $\mathrm{MS}^{2}$ spectra obtained in the negative ion mode from ${ }^{1} \mathrm{H}$ - and ${ }^{2} \mathrm{H}$ containing solvents were also consistent with the parent ion at $\mathrm{m} / \mathrm{z}, 235$ having the proposed structure.

To confirm the presence of the two $-\mathrm{OH}$ groups, the sample was permethylated and the product was analyzed using the ion trap mass spectrometer. It would be expected that both of these groups would be methylated, resulting in a total increase in mass of $28 \mathrm{Da}$. The positive ion mode mass spectrum showed an $\mathrm{m} / \mathrm{z}$ 265 ion, and the fragmentation pattern of that ion confirms the incorporation of the methyl groups onto the benzyl -OH groups, with major fragment ions at $\mathrm{m} / \mathrm{z}, 139,181$, and 223.

\section{Isolation of P. fluorescens PCL1606 derivatives impaired in antifungal metabolite production.}

A PCL1606 Tn5-luxAB transposon library consisting of more than 5,000 transposants was screened for decreased antagonistic activity against $D$. necatrix in the agar plate assay and subsequently for HPR production. From this library, two mutants, PCL1613 and PCL1614, were identified that were impaired in antagonistic activity. PCL1613 showed much reduced inhibition of $D$. necatrix and $F$. oxysporum. For mutant PCL1614, no fungal inhibition was observed. HPR production by the mutants was analyzed using TLC of chloroform and methanol extracts of spent growth medium. PCL1613 showed a very small HPR spot, whereas PCL1614 showed no detectable HPR spot (data not shown). PCL1613 and PCL1614 were not altered in exoenzymatic production and growth rate in comparison with the wild-type strain (data not shown).

The chromosomal insertion site of the transposon in mutants PCL1613 and PCL1614 was determined after reisolation of

Table 3. Nuclear magnetic resonance (NMR) spectroscopy analysis and proposed structure of the purified antifungal compound produced by Pseudomonas fluorescens PCL1606 ${ }^{\mathrm{a}}$

\begin{tabular}{|c|c|c|c|c|c|}
\hline \multirow[b]{2}{*}{ Center } & \multicolumn{2}{|c|}{${ }^{1} \mathrm{H}-\mathrm{NMR}$ (700 MHz) } & \multicolumn{2}{|c|}{${ }^{13} \mathrm{C}-\mathrm{NMR}$ (176.0 MHz) } & \multirow[b]{2}{*}{ Structure } \\
\hline & $\delta$ & Area, mult, $J_{\mathrm{HH}} / \mathrm{Hz}$ & $\delta$ & Area & \\
\hline $\mathrm{a}$ & 0.91 & $3 \mathrm{H}, \mathrm{t}, 8$ & 13.2 & $1 \mathrm{CH}_{3}$ & a $\mathrm{CH}_{3}$ \\
\hline b & & & 22.8 & $1 \mathrm{CH}_{2}$ & b $\mathrm{CH}_{1}$ \\
\hline $\mathrm{c}$ & $\{1.31$ & $6 \mathrm{H}, \mathrm{m}$ & 32.1 & $1 \mathrm{CH}_{2}$ & c $\mathrm{CH}_{2}$ \\
\hline d & & & 29.6 & $1 \mathrm{CH}_{2}$ & d $\mathrm{CH}_{2}$ \\
\hline $\mathrm{e}$ & 1.47 & $2 \mathrm{H}, \mathrm{m}$ & 29.4 & $1 \mathrm{CH}_{2}$ & e $\mathrm{CH}_{2}$ \\
\hline $\mathrm{f}$ & 2.53 & $2 \mathrm{H}, \mathrm{t}, 8$ & 23.0 & $1 \mathrm{CH}_{2}$ & $\mathrm{f}_{\mathrm{CH}}^{\prime}$ \\
\hline $\mathrm{g}$ & & & 113.0 & $1 \mathrm{C}$ & \\
\hline $\mathrm{h}$ & 4.80 & $2 \mathrm{H}, \mathrm{s}$ & 156.0 & $2 \mathrm{C}$ & \\
\hline i & 6.05 & $2 \mathrm{H}, \mathrm{s}$ & 107.0 & $2 \mathrm{CH}$ & \\
\hline $\mathrm{j}$ & & & 141.0 & $1 \mathrm{C}$ & $j$ \\
\hline $\mathrm{k}$ & 2.37 & $2 \mathrm{H}, \mathrm{t}, 8$ & 38.0 & $1 \mathrm{CH}_{2}$ & $\mathrm{k} \mathrm{CH}_{2}$ \\
\hline 1 & 1.57 & $2 \mathrm{H}, \mathrm{sex}, 8$ & 24.6 & $1 \mathrm{CH}_{2}$ & $\mathrm{CH}_{2}$ \\
\hline $\mathrm{m}$ & 0.94 & $3 \mathrm{H}, \mathrm{t}, 8$ & 13.5 & $1 \mathrm{CH}_{3}$ & $\mathrm{~m} \mathrm{CH}$ \\
\hline
\end{tabular}

${ }^{\mathrm{a}}$ NMR signals from 2-hexyl 5-propyl resorcinol (HPR). Structure of HPR deduced from ${ }^{1} \mathrm{H}-\mathrm{NMR}$ and ${ }^{13} \mathrm{C}-\mathrm{NMR}$ signals is shown in the last column.

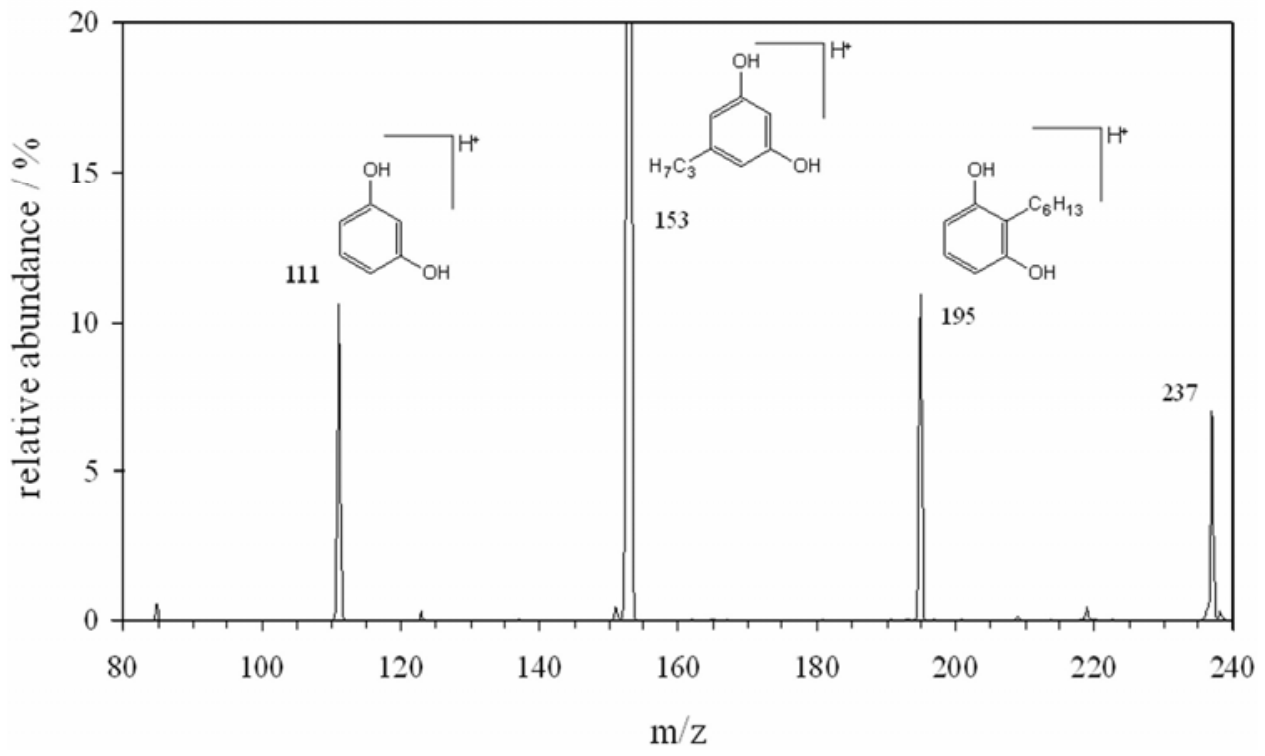

Fig. 4. Positive ion mode electrospray ion trap collision-induced disssociation mass spectral analysis and fragment ion assignment of precursor ion $m / z 237$. 
the transposon with adjacent chromosomal parts, which were sequenced and subsequently analyzed for the presence of open reading frames (ORF) and sequence homologies. The transposon in PCL1613 appeared to be inserted in an ORF that showed highest homology with predicted hydrolases or acyltransferases (alpha/beta hydrolase superfamily) of $P$. fluorescens PfO-1 (73\% identity at the amino acid level; protein identification number ZP 00262402). For PCL1614, it was shown that the transposon had inserted in an ORF with high homology to $g c v T$ (89\% identity at the amino acid level with GcvT of $P$. fluorescens $\mathrm{PfO}-1$; protein identification number $\mathrm{ZP}$ 00264790). Chromosomal sequences adjacent to the $\operatorname{Tn} 5$ inserted in PCL1613 and PCL1614 have been submitted to the GenBank database under accession numbers DQ073040, DQ073041, DQ073042, and DQ073043, respectively.

\section{Biological control}

of HPR mutants of P. fluorescens PCL1606.

Using the avocado-D. necatrix test system, it was shown that wild-type $P$. fluorescens PCL1606 is able to reduce the white root rot disease index from 73 , in the untreated control, to $46 \%$ (Fig. 5A). Strains PCL1613 and PCL1614 did not suppress disease formation (Fig. 5A).

When the tomato- $F$. oxysporum foot and root rot test system was used, it was shown that wild-type $P$. fluorescens PCL1606 is able to reduce the number of diseased plants from 75 , in the untreated control, to $29 \%$ (Fig. 5B). The derivative strain PCL1613 significantly suppressed disease formation but to a significantly

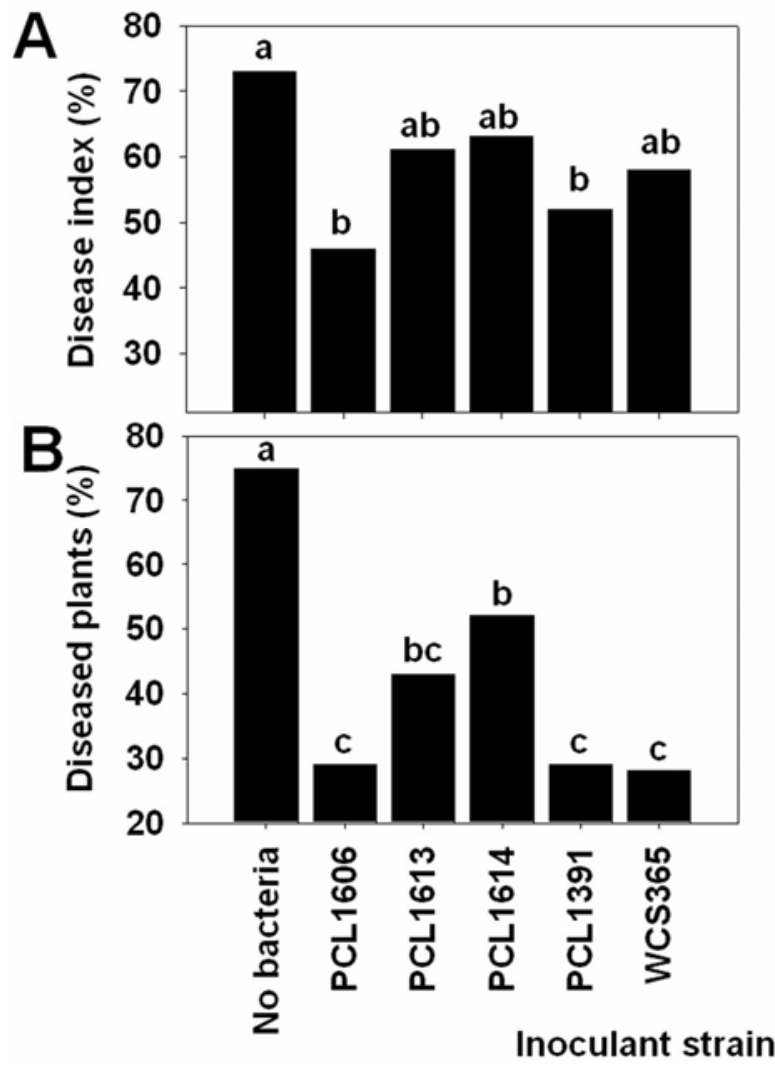

Fig. 5. Biocontrol ability of mutant derivatives of Pseudomonas putida PCL1606 impaired in antagonistic activity. Strains were tested on potting soil in $\mathbf{A}$, an avocado-D. necatrix system and $\mathbf{B}$, a tomato-Fusarium oxysporum f. sp. radicis-lycopersici system. Biocontrol strains Pseudomonas fluorescens WCS365 and P. chlororaphis PCL1391 were tested as controls. Data were analyzed for significance after arcsine square root transformation with analysis of variance, followed by Fisher's least significant difference test $(P=0.05)$. Values with different letter indications represent a statistically significant difference. higher value ( $43 \%$ diseased plants) when compared with its wild-type strain PCL1606. For the derivative strain PCL1614, the disease level recorded was higher $(52 \%)$ compared with PCL1613 but was still a statistically significant difference from the disease value observed in the untreated control.

\section{DISCUSSION}

The isolation of rhizobacterial strains from the rhizosphere of healthy avocado trees present in an area affected by soilborne phytopathogenic fungi represents a strategy for selecting microorganisms with antagonistic ability (Schroth and Hancock 1982). In this study, a set of eight Pseudomonas strains with high antagonistic ability against $D$. necatrix and other soilborne fungi was isolated (Table 1). Various typing methods, including BIOLOG, API20NE, and comparisons of the (partial) $16 \mathrm{~S}$ rDNA sequence provided consistent results in characterizing these strains (Table 1). Our results indicate that pseudomonads are one of the dominant culturable bacteria associated with the roots of avocado.

The selected antagonistic Pseudomonas spp. showed a very broad range of antagonistic activity against many phytopathogenic fungi tested, including Phytophthora cinnamomi, an oomycete that causes the most serious fungal disease on avocado plants worldwide (Erwin and Ribeiro 1996) and D. necatrix, which causes most of the crop losses in the Mediterranean area. The antagonistic activity of the isolated Pseudomonas spp. against the five strains of $D$. necatrix tested was generally high. The percentage of isolated antagonistic Pseudomonas sp. strains was similar to the percentage $(1 \%)$ previously observed for isolation of antagonistic bacteria from the tomato rhizosphere of plants grown in southern Spain (Chin-A-Woeng et al. 1998).

Antifungal compounds produced by the $D$. necatrix-antagonistic Pseudomonas spp. were analyzed. Strains of $P$. chlororaphis (PCL1601, PCL1604, PCL1607, and PCL1611) produce PCA as well as PCN (Table 2 and Fig. 1), and these metabolites have been shown to be involved directly in the suppression of take-all disease of wheat, caused by Gaeumannomyces graminis var. tritici (Thomashow and Weller 1988) and in the inhibition of tomato foot and root rot caused by $F$. oxysporum f. sp. radicis-lycopersici (Chin-A-Woeng et al. 1998), and they can also enhance the biocontrol of non-PCA producing strains (Huang et al. 2004). P. fluorescens PCL1606 produced proteases, lipases, and an antifungal metabolite (Fig. 1, S) that is different from a range of defined compounds used as standards. Purification followed by structural analysis (Table 3, Fig. 4) showed that this antifungal metabolite is HPR, a compound with antimicrobial properties that could be related to PRN (Gaffney et al. 1994; Nowak-Thompson et al. 2003).

The $P$. putida strains PCL1603 and PCL1609 and $P$. fluorescens PCL1602 do not produce antifungal antibiotics but only a very small amount of HCN (Table 2), which could be responsible for the moderate antagonistic activity against the fungi studied (Table 1).

Some strains did not show biocontrol activity in either of the two biocontrol systems (Fig. 3), despite their antifungal activity on agar plate tests (Table 1). This lack of biocontrol activity in the rhizosphere environment in vitro by antagonistic strains has been reported before (Chin-A-Woeng et al. 1997) and could be due to poor colonization of the root system and, therefore, poor delivery of antifungal metabolites along the root system (Chin-A-Woeng et al. 2000; Lugtenberg et al. 2001). Alternatively, the production of antifungal metabolites, which is very sensitive to environmental conditions (Duffy and Defago 1999) may be reduced or not occur in the root environment (Fiddaman and Rossall 1994). 
The strains $P$. chlororaphis PCL1601 and P. fluorescens PCL1606 appeared to have the strongest activity against $D$. necatrix of the eight avocado rhizobacterial Pseudomonas antagonistic strains (Fig.2). These strains were found to have a significant ability to biocontrol Dermatophora root rot of avocado when grown in inert substrate vermiculite (Fig. 2A) as well as in complex substrate potting soil (Fig. 2B). The slightly lower levels of disease observed when using potting soil as a substrate could be due to the complex interactions of D. necatrix with either the substrate, other microorganisms, or both, as described for the phytopathogenic oomycete $P$. cinnamomi in the presence of organic material (Downer et al. 2002). The degree of biocontrol activity of the new isolates P. chlororaphis PCL1601 and P. fluorescens PCL1606 results in a lower disease index than that of the control strains $P$. chlororaphis PCL1391 (Chin-A-Woeng et al. 1998) and $P$. fluorescens WCS365 (Dekkers et al. 2000) (Figs. 2 and 3). This shows that these latter two strains, which are efficient in the tomato-Fusarium test system and which control tomato foot and root rot by different mechanisms, are not specific in controlling a particular disease but may be broadly applicable.
This is the first report of an avocado- $D$. necatrix biocontrol test system, used with the purpose of selecting plant growthpromoting rhizobacteria to be used as biocontrol agents.

The use of the tomato-Fusarium test system revealed that most of the newly isolated strains described in this paper gave a significant reduction in the disease symptom levels (Fig. 3). This observation suggests a higher sensitivity of the tomato-Fusarium test system to biocontrol than the avocado-Dematophora test system, but it shows that the utilization of the avocado-Dematophora test system is necessary to select good biocontrol strains for $D$. necatrix. The new isolates $P$. chlororaphis PCL1601 and $P$. fluorescens PCL1606 also appeared to be the best biocontrol strains in this tomato-Fusarium test system, with disease indices of $77 \%$ in plants without bacterial treatment and 26 and $30 \%$ in plants treated with $P$. fluorescens PCL1606 and P. chlororaphis PCL1601, respectively (Fig. 3), suggesting that these two strains can also be applied against different fungal pathogens and that their biocontrol activity is not specific.

Strain PCL1606, the most active of the antagonistic isolates selected, was found to have a significant biocontrol activity against Dematophora root rot of avocado (Figs. 2 and 5A) and foot and root rot of tomato (Figs. 3 and 5B). The antibiotic pro-

Table 4. Bacterial strains and plasmids used in this study

\begin{tabular}{|c|c|c|}
\hline Strain or plasmid & Relevant characteristics & Reference or source \\
\hline \multicolumn{3}{|l|}{ Bacterial strains } \\
\hline DH5 $\alpha$ & General-purpose Escherichia coli host strain; donor strain of pRL1063a in conjugation experiments & Boyer and Roulland-Dussoix 1969 \\
\hline K12 HB101 & $\begin{array}{l}\text { General-purpose } E \text {. coli host strain; helper strain harboring the plasmid pRK2013, used in } \\
\text { conjugation experiments }\end{array}$ & Figurski and Helinski 1979 \\
\hline PCL1391 & $\begin{array}{l}\text { Wild-type Pseudomonas chlororaphis, producing phenazine-1-carboxamide and biocontrol } \\
\text { strain of tomato foot and root rot caused by Fusarium oxysporum f. sp. radicis-lycopersici. }\end{array}$ & Chin-A-Woeng et al. 1998 \\
\hline PCL1601 & Wild-type $P$. chlororaphis, isolated from Spanish avocado rhizosphere & This study \\
\hline PCL1602 & Wild-type $P$. fluorescens, isolated from Spanish avocado rhizosphere & This study \\
\hline PCL1603 & Wild-type $P$. putida, isolated from Spanish avocado rhizosphere & This study \\
\hline PCL1604 & Wild-type $P$. chlororaphis, isolated from Spanish avocado rhizosphere & This study \\
\hline PCL1606 & Wild-type $P$. fluorescens, isolated from Spanish avocado rhizosphere; nal $^{\mathrm{r}}$ & This study \\
\hline PCL1607 & Wild-type $P$. chlororaphis, isolated from Spanish avocado rhizosphere & This study \\
\hline PCL1609 & Wild-type $P$. putida, isolated from Spanish avocado rhizosphere & This study \\
\hline PCL1611 & Wild-type $P$. chlororaphis, isolated from Spanish avocado rhizosphere & This study \\
\hline PCL1613 & PCL1606 derivative in which a promoterless $\operatorname{Tn} 5 \operatorname{lux} A B$ has been inserted. & This study \\
\hline PCL1614 & PCL1606 derivative in which a promoterless Tn5luxAB has been inserted. & This study \\
\hline Pf5 & $\begin{array}{l}\text { Wild-type } P \text {. fluorescens, producing DAPG, PLT, and PRN, and biocontrol strain of cotton } \\
\text { damping off caused by Rhizoctonia solani. }\end{array}$ & Howell and Stipanovic 1979 \\
\hline WCS365 & $\begin{array}{l}\text { Wild-type Pseudomonas fluorescens, efficient competitive colonizer of roots and biocontrol } \\
\text { strain of tomato foot and root rot caused by } F \text {. oxysporum f. sp. radicis-lycopersici }\end{array}$ & $\begin{array}{l}\text { Geels and Schippers, 1983; } \\
\text { Simons et al. } 1996\end{array}$ \\
\hline \multicolumn{3}{|c|}{ ( } \\
\hline pRL1063a & Plasmid harboring Tn 5 transposon containing promoterless $l u x A B ; \mathrm{km}^{\mathrm{r}}$ & Wolk et al. 1991 \\
\hline pRK2013 & Contains RK12 genes; helper plasmid for mobilization on non-self transmissible plasmids; $\mathrm{km}^{\mathrm{r}}$ & Figurski and Helinski 1979 \\
\hline
\end{tabular}

${ }^{\mathrm{a}}$ nal $^{\mathrm{r}}=$ nalidixic acid resistant, $\mathrm{DAPG}=2,4$-diacetylphloroglucino, $\mathrm{PLT}=$ pyoluteorin, $\mathrm{PRN}=$ pyrrolnitrin, and $\mathrm{km}^{\mathrm{r}}=\mathrm{kanamycin} \mathrm{resistant}$.

Table 5. Fungal strains used in this study

\begin{tabular}{|c|c|c|}
\hline Strain designation & Relevant characteristics $^{a}$ & Reference or source $^{b}$ \\
\hline \multicolumn{3}{|l|}{ Dematophora necatrix } \\
\hline 400 & Wild-type, isolated from Drr; High virulence & Pérez-Jiménez 1997 \\
\hline 397 & Wild-type, isolated from Drr; medium virulence & Pérez-Jiménez 1997 \\
\hline 358 & Wild-type isolated isolated from Drr; low virulence & Pérez-Jiménez 1997 \\
\hline CECT2817 & Isolated from avocado pear rot & CECT, Valencia, Spain \\
\hline СЕCT2818 & Isolated from avocado pear rot & CECT, Valencia, Spain \\
\hline \multicolumn{3}{|l|}{ Phytophthora cinnamomi } \\
\hline 344 & Wild-type, isolated from Prr; Low virulence & Pérez-Jiménez 1997 \\
\hline 301 & Wild-type, isolated from Prr; medium virulence & Pérez-Jiménez 1997 \\
\hline 273 & Wild-type, isolated from Prr; High virulence & Pérez-Jiménez 1997 \\
\hline Pythium ultimum LBOP17 & Can causes avocado root rot, pathogen to many plants & IPO-DLO, Wageningen, The Netherlands \\
\hline Rhizoctonia solani 3R4FNA & Can causes Rhizoctonia seed and root rot of avocado; pathogen to many plants & IPO-DLO, Wageningen, The Netherlands \\
\hline Sclerotium rolfsii 151.31 & Can causes avocado seedling blight, pathogen to many plants & CBS, Utrecht, The Netherlands. \\
\hline Verticillium dahliae CECT2694 & Can causes Verticillium wilt of avocado; pathogen to many plants. & CECT, Valencia, Spain. \\
\hline Fusarium oxysporum f. sp. & & \\
\hline radicis-lycopersici ZUM2407 & Causes crown and foot rot of tomato & IPO-DLO Wageningen, The Netherlands \\
\hline
\end{tabular}


duced by $P$. fluorescens PCL1606 was shown to be HPR, an antifungal compound reported previously to be produced by Pseudomonas spp. with antimicrobial activity (Kanda et al. 1975; Kitahara and Kanda 1975; Nowak-Thompson et al. 2003). The role in biocontrol of HPR was studied by using derivative strains impaired in HPR production. The reduced biocontrol ability of HPR derivative mutants PCL1613 with reduced HPR production and PCL1614, a HPR-negative mutant, in the avocado- $D$. necatrix and tomato- $F$. oxysporum biocontrol test systems strongly suggests that HPR forms an essential determinant of the biocontrol mechanism of P. fluorescens PCL1606 (Fig 5). As far as we know, this is the first report of a Pseudomonas strain that produces HPR in which the production of this compound is shown to be crucial for biocontrol activity. Functions of the mutated genes or downstream genes present in the inserted operon in the production of HPR are being clarified in more detail in a follow-up study. The predicted gene product of the mutated gene of PCL1613 shows similarity to enzymes with acyltransferase activity, which could fit into a putative synthetic pathway of HPR, which contains acyl chains bound to the aromatic resorcinol group. Previous studies have described incorporation of acetate into the alkylresorcinol moiety (Achenbach et al. 1982; Sankawa et al. 1981).

For PCL1614, the mutated gene shows high homology with a glycine cleavage protein system, with an aminomethyl transferase activity, which can catalyze the transfer of an aminomethyl or methyl moiety from the substrates to ring-based molecules, such as H4folate (Masai et al. 2004), and could fit into a putative synthetic pathway of HPR by adding $\mathrm{C}$ atoms to the precursor molecule.

The disrupted genes in PCL1613 and PCL1614 are different from those described for the biosynthetic pathways of HPR in Pseudomonas aurantiaca (Nowak-Thompson et al. 2003), suggesting a new biosynthetic pathway (or a branch) for HPR synthesis in P. fluorescens PCL1606.

In both biocontrol systems, the disease suppression produced by the derivative mutants is lower than that obtained with the wild-type strain, although disease levels do not reach those of untreated plants. This could mean that other traits could also be involved in the biocontrol activity of PCL1606, such as colonization or induction of defense systems (Lugtenberg et al. 2001).

\section{MATERIALS AND METHODS}

\section{Microorganisms, culture, and conditions.}

The bacterial strains used in this study are listed in Table 4. $\mathrm{KB}$ was used routinely for culturing Pseudomonas spp. strains at $24^{\circ} \mathrm{C}$. Luria-Bertani medium (LB) (Bertani 1951) was used for culturing Escherichia coli strains at $37^{\circ} \mathrm{C}$. The bacterial strains were stored for preservation at $-80^{\circ} \mathrm{C}$ in $15 \%$ glycerol. Media were supplemented with kanamycin to a final concentration of $50 \mu \mathrm{g} / \mathrm{ml}$ when required.

The fungal strains used in this study (Table 5) were grown at $24^{\circ} \mathrm{C}$ on potato dextrose agar (PDA) (Difco Laboratories, Detroit) or $\mathrm{KB}$ and were stored at $4^{\circ} \mathrm{C}$ in water. They were routinely replicated every six months on PDA to test viability.

\section{Isolation of bacteria from avocado rhizosphere.}

Rhizobacterial strains were isolated from the rhizosphere of healthy avocado trees from areas affected by root pathogens. Roots were sampled from 20-year-old healthy avocado trees located in different orchards in Algarrobo, Fuengirola, and Vélez-Málaga (Málaga, Spain). The experimental sites were naturally affected by Dematophora root rot. In each sampling orchard, samples were taken from different types of soil (slate, clay, and sandy soils). Roots were collected from avocado trees at a distance of $1 \mathrm{~m}$ from the trunk and $10 \mathrm{~cm}$ from the soil surface. The root samples were gently shaken to remove loosely adhering soil and were aseptically transferred to storage bags. The roots were maintained on ice and were transported to the laboratory, where they were immediately stored at $-80^{\circ} \mathrm{C}$ before processing.

A total of 24 root samples were analyzed. Root samples were washed twice in tap water and were weighed and homogenized in a lab blender for 3 min with $10 \mathrm{ml}$ of sterile phosphate buffered saline (PBS), $\mathrm{pH} 7.2$, per gram of fresh root material. Suspensions were diluted 10 -fold. In order to evaluate the amount of culturable bacteria, suspensions were plated on TSA (Oxoid, Perth, U.K.) amended with cycloheximide $(100 \mu \mathrm{g} / \mathrm{ml})$ to prevent fungal growth and on $\mathrm{KB}$ with cycloheximide and PI (Difco Laboratories, Detroit) to recover Pseudomonas-like strains. Plates were incubated at $24^{\circ} \mathrm{C}$ for 48 to $72 \mathrm{~h}$. After incubation, colony numbers and morphology characteristics were recorded. The most abundant colonies with different morphology were plated on TSA and KB agar.

\section{Antagonistic activity.}

Antagonistic activity of rhizobacterial isolates was tested as described previously (Geels and Schippers 1983). Initial screening for in vitro antifungal activity on $\mathrm{KB}$ and PDA agar plates against $D$. necatrix 400 was performed by placing on the agar in the center of a petri dish a $0.6-\mathrm{cm}$ diameter mycelium disk from a 5-day-old fungal culture grown at $24^{\circ} \mathrm{C}$, followed by inoculation of the bacterial strains at a distance of about $3 \mathrm{~cm}$ from the fungus. Bacterial strains inhibiting mycelial growth after five days of growth, as judged by a growth inhibition zone, were selected for further characterization. For the selected bacterial isolates, a second trial of in vitro inhibition of fungi was carried out against a number of other avocado and plant fungal pathogens (Table 5). These assays were performed in the same way as described above.

\section{Characterization of bacterial isolates.}

A number of phenotypic and physiological tests were performed to characterize the selected antagonistic bacterial isolates by using the API20NE (BioMerieux, Mercy L'etoyle, France) and BIOLOG (Biolog Inc., Hayward, CA, U.S.A.) systems. Further characterization was performed by analysis of the $16 \mathrm{~S}$ rDNA sequence. For this, colony PCR was performed on the selected strains, using the primers $41 \mathrm{~F}\left(5^{\prime}\right.$-GCT CAG ATT GAA CGC TGG CG-3') and 1486-N (5'-GCT ACC TTG TTA CGA CTT CAC CCC-3'), described by Stackebrandt and Goodfellow (1991). A single colony from a 24- to 48-h culture on a KB plate was suspended in $20 \mu \mathrm{l}$ of sterile water. Subsequently, $1.0 \mathrm{ml}$ of a $0.05 \mathrm{M} \mathrm{NaOH}$ and $0.25 \%$ SDS (sodium dodecyl sulphate) solution was added and the mixture was incubated at $95^{\circ} \mathrm{C}$ for 15 min. Ten microliters of a 10 -fold dilution of this suspension in sterile water was used as a template in a PCR reaction with a hot start for $120 \mathrm{~s}$ at $95^{\circ} \mathrm{C}$, followed by 10 cycles consisting of $40 \mathrm{~s}$ at $94^{\circ} \mathrm{C}, 60 \mathrm{~s}$ at a decreasing temperature gradient of $1^{\circ} \mathrm{C}$ per cycle starting from $60^{\circ} \mathrm{C}, 120 \mathrm{~s}$ at $72^{\circ} \mathrm{C}$, and subsequently, 25 cycles consisting of $40 \mathrm{~s}$ at $94^{\circ} \mathrm{C}, 60 \mathrm{~s}$ at $50^{\circ} \mathrm{C}, 120 \mathrm{~s}$ at $72^{\circ} \mathrm{C}$, and a final extension of $72^{\circ} \mathrm{C}$ for $120 \mathrm{~s}$. The resulting PCR fragment was purified (QIAquick PCR purification kit 50; Westburg, Leusden, The Netherlands) and was used directly for sequencing (Baseclear, Leiden, The Netherlands). The sequence was analyzed using DNAman software (Lynnon Biosoft, Quebec, Canada). Homology studies were carried out using National Center for Biotechnology Information GenBank Blast software (Bethesda, MD, U.S.A.).

\section{Characterization of antifungal metabolites.}

The selected Pseudomonas strains were tested for production of HCN (Castric 1975), protease, lipase, $\beta$-glucanase, and 
cellulase by general procedures described previously (Gerhardt 1994). Detection of antifungal metabolites was performed by silica TLC.

Analysis of phenazines was carried out after extraction of 2day-old culture supernatants (KB and LB medium) with acetonitrile (Chin-A-Woeng et al. 1998). RP-18F 254 s TLC plates (Merck AG, Darmstadt, Germany) were developed with chloroform/acetone $(9: 1, \mathrm{vol} / \mathrm{vol})$ for $2 \mathrm{~h}$. The presence of spots with $R_{f}$ values of 0.45 and 0.78 under UV light $(254 \mathrm{~nm})$ was indicative of the presence of PCA and PCN, respectively.

For detection of the antibiotics DAPG, PRN, and PLT, extractions of 4-day-old supernatant cultures were carried out with chloroform/methanol $(2: 1, \mathrm{vol} / \mathrm{vol})$. Extracted material was fractionated by silica TLC using chloroform/acetone (9:1, vol/vol). After drying, the chromatogram was observed under UV light and was sprayed with DASA (Whistler et al. 2000). Antibiotics were preliminarily identified by their characteristic color and $R_{f}$ values, corresponding to those of authentic standards: PLT, $R_{f}=0.32$, brown; PRN, $R_{f}=0.81$, maroon; and DAPG, $R_{f}=0.64$, yellow.

To analyze the antifungal activity of the different fractions after chromatographic analysis, TLC plates were run in duplicate, and the different spots were located on one TLC plate while the other TLC plate was used to recover the fractions by extraction. To extract the spots, silica regions were scratched off the plate and were extracted overnight with acetonitrile/water $(70: 30 \mathrm{vol} / \mathrm{vol})$. The extract was concentrated by evaporation, and its activity was tested against $D$. necatrix as follows. Extract $(10 \mu \mathrm{l})$ was placed on paper $0.5-\mathrm{cm}$ diameter filter disks, which were dried and placed on a 12-well plate (Lucron Bioproducts, Gennep, The Netherlands) containing a layer of $250 \mu \mathrm{l}$ of $\mathrm{KB}$ agar on the bottom to avoid dehydratation. Finally, a disk of mycelium was placed on the top of each disk. After three days, visual inhibition of fungal growth was recorded. To test the antifungal activity of the extracted fractions against $F$. oxysporum, a TLC bioassay was carried out as described previously (Chin-A-Woeng et al. 1998).

\section{Growth of avocado plants for biocontrol tests.}

To develop a new avocado- $D$. necatrix biocontrol test system, avocado plants were obtained by growing seedlings from avocado embryos (Pliego-Alfaro et al. 1987). Briefly, avocado seeds (cvs. Reed and Topa-Topa) were disinfected by immersion in a solution containing $0.5 \%$ sodium hypochlorite and $0.1 \%$ Tween 20 . Subsequently, they were split into two separate cotyledons, excising the plumule-radicle axes together with 1- to 2-cm-thick cotyledon sections, and were transferred in sterile nutrient tubes containing Murashige and Skoog medium (Murashige and Skoog 1962), the $\mathrm{pH}$ of which was adjusted to 5.7 before adding $0.6 \%$ agar. Each $25 \times 150-\mathrm{mm}$ tube contained $25 \mathrm{ml}$ of nutrient medium. The tubes were capped with polypropylene stoppers (Bellco Glass, Inc., Vineland, NJ, U.S.A.) and were autoclaved. One plumule-radicle axis was placed in each tube, which was incubated in a growth chamber at $24^{\circ} \mathrm{C}$ with $16 \mathrm{~h}$ of daily light exposure.

After four weeks, the seedling shoots were removed from the tubes, the roots were washed with tap water and were placed in pots containing $30 \mathrm{~g}$ of wet perlite (Agra-perlite, Maasmond Westland B.A., Rijnsburg, The Netherlands). The seedlings were maintained in a growth chamber for 20 to 30 days in order to harden the roots, after which the avocado plants were ready to be used in biocontrol experiments.

\section{Avocado-Dematophora biocontrol test.}

Dematophora necatrix inoculum was produced on wheat seeds (Freeman et al. 1986). Briefly, the seeds were soaked for $12 \mathrm{~h}$ in $250-\mathrm{ml}$ Erlenmeyer flasks filled with distilled water.
The flasks, each containing $100 \mathrm{ml}$ of seeds, were subsequently autoclaved, after excess water had been drained off. After sterilization, three fungal disks of a 2-week-old culture of D. necatrix grown on $\mathrm{KB}$ were placed aseptically in each flask. Flasks were subsequently incubated at $24^{\circ} \mathrm{C}$ in the light for two weeks, unless otherwise stated, and were shaken every two to three days to avoid clustering of seeds.

Plants with hardened roots were removed from the perlite, and the roots were washed with tap water in order to remove remaining perlite. The roots of the seedlings were surface disinfected by immersion in $0.1 \% \mathrm{NaOCl}$ for $20 \mathrm{~min}$ and were washed.

The roots were then bacterized, following a similar method to that previously described (Lugtenberg et al. 1994). Roots of avocado seedlings were immersed in a suspension of the bacterial isolate $\left(10^{9} \mathrm{CFU} / \mathrm{ml}\right)$ or in sterile tap water as a control for $20 \mathrm{~min}$. Excess suspension was allowed to drip off, and the seedlings were placed in pots containing $30 \mathrm{~g}$ of wet vermiculite or potting soil (Jongkind Grond B.V., Aalsmeer, The Netherlands) infected with $D$. necatrix using wheat grains (four infected grains per pot).

Fifty plants were tested per treatment in series of 10 plants each. Seedlings were grown in a growth chamber at $24^{\circ} \mathrm{C}, 70 \%$ relative humidity, and $16 \mathrm{~h}$ of daylight. Plants were watered twice per week from above ( $25 \mathrm{ml}$ each time). The number of diseased plants was determined when a substantial number of the plants $(>60 \%)$ in the untreated control were diseased, usually between 14 and 21 days after the bacterization.

Because of the difficulty of observing the symptoms on the hardened avocado roots and because of the broad development of $D$. necatrix, we calculated the disease index percentage of foliar symptoms. Disease index percentage was recorded after evaluation of aerial symptoms, with values ranging from 0 (healthy plant), 1 (yellowing and wilting of the leaves), 2 (overall drying of the plant), to 3 (dead plant), using the following previously described formula (Teixeira de Sousa 1985).

$$
\mathrm{DI}=100 \times \frac{(a \times 0)+(b \times 1)+(c \times 2)+(d \times 3)}{3 \times n}
$$

where $a, b, c$, and $d$ correspond to the number of plants showing evaluation disease values of $0,1,2$, and 3 , respecttively, and $n$ is the total number of plants tested.

\section{Biocontrol of tomato foot and root rot.}

Tomato-Fusarium oxysporum f. sp. radicis-lycopersici bioassays were performed as described previously (Chin-AWoeng et al. 1998). One third of a 10-day-old PDA plate culture of $F$. oxysporum f. sp. radicis-lycopersici was homogenized and inoculated in $200 \mathrm{ml}$ of Czapek-Dox medium in a 1liter Erlenmeyer flask. After growth for three days at $28^{\circ} \mathrm{C}$ under aeration $(110 \mathrm{rpm})$, the fungal material was placed on top of sterile glass wool and the filtrate was adjusted to a concentration of $5.7 \mathrm{log}$ spores per milliliter. For inoculation, spores were mixed thoroughly with potting soil to a final concentration of $6.5 \mathrm{log}$ spores per kilogram.

Tomato (Lycopersicon esculentum Mill.) seeds (cv. Carmello) were coated with bacteria by dipping the seeds in a mixture of $1 \%$ (wt/vol) methylcellulose (Sigma, St. Louis) and $9 \log$ CFU bacteria per milliliter in PBS buffer. Coated seeds were dried in a sterile stream of air. In a pot containing $25 \mathrm{~g}$ of soil, one seed was sown per pot, at a depth of approximately $1.5 \mathrm{~cm}$. Ten series of 10 plants were tested per treatment. Seedlings were grown in a greenhouse at $24^{\circ} \mathrm{C}, 70 \%$ relative humidity, and $16 \mathrm{~h}$ of daylight. Plants were watered from the bottom. The number of diseased plants was determined when a substantial number of the plants $(>60 \%)$ in the untreated control were diseased, usually 18 days after sowing. Plants were 
removed from the soil and were washed, and the plant roots were examined for crown and root rot indicated by root browning and lesions. Roots without any disease symptoms were classified as healthy.

\section{Statistical methods.}

Data were statistically analyzed using analysis of variance (Sokal and Rohlf 1986) followed by Fisher's least significant difference test $(P=0.05)$, using SPSS software (SPSS Inc., Chicago). All experiments were performed at least twice.

\section{Purification of the antifungal compound produced by $P$. fluorescens PCL1606.}

For the purification of the antifungal compound produced by $P$. fluorescens PCL1606, the antifungal spot was extracted from TLC as described above and was fractionated by HPLC performed with an Alltech Econosphere C8 column $(5 \mu \mathrm{m}$, $250 \times 4.6 \mathrm{~mm}$ ) (Alltech Associates, Inc., Deerfield, IL, U.S.A.). Samples were eluted isocratically with $50 \%$ acetonitrile in water with a flow rate of $1 \mathrm{ml} / \mathrm{min}$. UV detection was performed with a Pharmacia RSD 2140 diode array detector (Pharmacia, Uppsala, Sweden) with wave-length detection from 190 to $400 \mathrm{~nm}$, and 1.0-ml fractions were collected for testing antifungal activity as previously described. Fractions exhibiting antifungal activity were dried and collected for mass spectrometry and NMR analysis.

\section{Mass spectrometric and NMR analyses.}

NMR measurements were carried out on a Jeol ECA 700, using an inverse geometry $5-\mathrm{mm}^{1} \mathrm{H}$ and ${ }^{13} \mathrm{C}$ probe (Jeol, Tokyo, Japan) and a Bruker AMX 500, using a Protasis microcoil probe. A Hewlett Packard (Palo Alto, CA, U.S.A.) 5890 MSD electron impact instrument was used for GC-MS analysis. Sample solution $(1 \mu \mathrm{l})$ in methanol was injected using spitless injection, and separation was performed using a DB-5 MS column $(0.32 \times 30 \mathrm{~m}$; J \& W Scientific, Folsom, CA, U.S.A. $)$, with helium as the carrier gas and the following temperature program: $40^{\circ} \mathrm{C}$ (held $1 \mathrm{~min}$ ), followed by a linear temperature gradient at $6^{\circ}$ per min to $240^{\circ} \mathrm{C}$ (held isothermal for $10 \mathrm{~min}$ ). The accurate mass measurement was carried out on a VG Autospec (VG Analytical, Manchester, U.K.) standard magnetic sector instrument with voltage scanning and perfluorokerosene as calibrant, using electron ionization. Electrospray ionization tandem mass spectra were collected from samples dissolved in protonated or deuterated (following NMR) methanol containing $0.1 \%$ formic acid using a LCQ DECA XP Plus (Thermo Electron, Hemel Hempstead, U.K.) ion trap mass spectrometer. The electrospray voltage used was $4,500 \mathrm{~V}$, the temperature of the heated inlet capillary was $185^{\circ} \mathrm{C}$, and the sample solution was infused at 1 to $2 \mu \mathrm{l} \mathrm{min}^{-1}$. Permethylation was carried out using the method of Ciucanu and Kerek (1984) as described by Boone and associates( 1999).

\section{Isolation of PCL1606 mutants impaired in antagonistic activity.}

A Tn5 transposon library of $P$. fluorescens PCL1606 was generated with pRL1063a harboring a promoterless Tn5luxAB transposon (Wolk et al. 1991), as described by Kragelund and associates (1995). Conjugation experiments were carried out using E. coli DH5 $\alpha$ pRL1063a as donor strain, E. coli K12 HB101 harboring plasmid pRK2013 as helper, and P. fluorescens PCL1606 as recipient, selecting the transposants on TSA supplemented with nalidixic acid $\left(15 \mu \mathrm{g} \mathrm{ml}^{-1}\right)$ and kanamycin $\left(30 \mu \mathrm{g} \mathrm{ml}^{-1}\right)$. Antifungal mutants were identified by loss of antagonistic activity on a plate assay and loss of the antifungal spot as detected by the TLC detection analysis. The selected mutants were characterized for uniformity with the wild-type strain by using the BIOLOG and API tests. Growth of these selected mutants in rich and minimal media was monitored, and the resistance or sensitivity to different concentrations of the antibiotics rifampicin (from 0 to $100 \mu \mathrm{g} \mathrm{ml}^{-1}$ ), lysozyme (from 0 to $10,000 \mu \mathrm{g} \mathrm{ml}^{-1}$ ), and erythromycin (from 0 to 1,000 $\mu \mathrm{g} \mathrm{ml}^{-1}$ ) was surveyed to avoid mutants with altered membrane permeability (López-Solanilla et al. 1998).

To isolate the DNA region flanking the Tn5, total genomic DNA was isolated and digested with EcoRI, which does not cut pRL1063a. Digested genomic DNA fragments were recircularized and were selected for kanamycin resistance, resulting in plasmids containing genomic DNA regions flanking the Tn5luxAB. All DNA techniques were performed as described in Sambrook and Russel 2001.

\section{ACKNOWLEDGMENTS}

The authors thank R. Pérez and C. López Herrera for supplying some D. necatrix and P. cinnamomi strains, A. Barceló for technical assistance with growing the avocado plants in vitro, T. Chin-A-Woeng for helpful assistance in TLC and HPLC analyses, J. M. Farré for helpful suggestions, and A. de Vicente for his suggestions and for critically reading the manuscript. E. T. Bergström and J. Thomas-Oates are grateful to T. Dransfield, Department of Chemistry, University of York, for acquiring the high-resolution EI mass spectrum, and to I. Fleet, Department of Chemistry, UMIST, for recording the GC-MS data. S. B. Duckett and J. Thomas-Oates are grateful for financial support from the Biotechnology and Biological Sciences Research Council (grant number REI18489). J. Thomas-Oates also gratefully acknowledges financial support from the Analytical Chemistry Trust Fund, the RSC Analytical Division, the EPSRC, and support from Thermo Electron. We are grateful to Jeol for help with obtaining appropriate spectra and for making the spectrometer available and to Protasis for the loan of a microcoil NMR probe. This research has been supported by a Marie Curie Fellowship of the European Community program Improving Human Potential under contract number HPMF-CT-1999-00377.

\section{LITERATURE CITED}

Achenbach, H., Boettger-Vetter, A., Fautz, E., and H. Reichenbach. 1982. On the origin of the branched alkyl substituents on ring B of flexirubintype pigments. Arch. Microbiol. 132:241-244.

Becker, J. O., and Cook, R. J. 1988. Role of siderophores in suppression of Pythium species and production of increased-growth response of wheat by Pseudomonads. Phytopathology 78:778-782.

Bertani, G. 1951. Studies on lysogenesis. 1: The mode of phage liberation by lysogenic Escherichia coli. J. Bacteriol. 62:293-300.

Boyer, H. W., and Roulland-Dussoix, D. 1969. A complementation analysis of the restriction and modification of DNA in Escherichia coli. J. Mol. Biol. 41:459-472.

Boone, C. M., Olsthoorn, M. M. A., Dakora, F. D., Spaink, H. P., and Thomas-Oates J. E. 1999. Structural characterization of lipo-chitin oligosaccharides isolated from Bradyrhizobium aspalati, microsymbionts of commercially important South African legumes. Carbohydr. Res. 317:155-163.

Budzikiewicz, K. 1993. Secondary metabolites from fluorescents pseudomonads. FEMS (Fed. Eur. Microbiol. Soc.) Microbiol. Rev. 10:209-228.

Castric, P. A. 1975. Hydrogen cyanide, a secondary metabolite of Pseudomonas aeruginosa. Can. J. Microbiol. 21:613-618.

Chin-A-Woeng, T. F. C., Bloemberg, G. V., van der Bij, A. J., van der Drift, K. M. G. M., Schripsema, J., Kroon, B., Scheffer, R. J., Keel, C., Bakker, P. A. H. M., Tichy, H.-V., de Bruijn, F. J., Thomas-Oates, J. E., and Lugtenberg, B. J. J. 1998. Biocontrol by phenazine-1-carboxamideproducing Pseudomonas chlororaphis PCL1391 of tomato root rot caused by Fusarium oxysporum f. sp. radicis-lycopersici. Mol. PlantMicrobe Interact. 11:1069-1077.

Chin-A-Woeng, T. F. C., Bloemberg, G. V., Mulders, I. H. M., Dekkers, L. C., and Lugtenberg, B. J. J. 2000. Root colonization by the phenazine1-carboxamide producing bacterium Pseudomonas chlororaphis PCL1391 is essential for biocontrol of tomato foot and root rot. Mol. Plant-Microbe Interact. 13:1340-1345.

Chin-A-Woeng, T. F. C., de Priester, W., van der Bij, A. J., and Lugtenberg, B. J. J. 1997. Description of the colonization of a gnotobiotic tomato rhizosphere by Pseudomonas fluorescens biocontrol strain WCS365, using scanning electron microscopy. Mol. Plant-Microbe Interact. 10:79-86. 
Ciucanu, I., and Kerek F. 1984. A simple and rapid method for the permethylation of hydrocarbons. Carbohydr. Res. 131:209-217.

de Weger, L. A., van der Bij, A. J., Dekkers, L. C., Simons, M., Wijffelman, C., and Lugtenberg, B. J. J. 1995. Colonization of the rhizosphere of crop plants by plant-beneficial pseudomonads. FEMS (Fed. Eur. Microbiol. Soc.) Microbiol. Ecol. 17:221-227.

Dekkers, L. C., Mulders, I. H. M., Phoelich, C. C., Chin, T. F. C., Wijfjes, A. H. M., and Lugtenberg, B. J. J. 2000. The sss colonization gene of the tomato-Fusarium oxysporum f. sp. radicis-lycopersici biocontrol strain Pseudomonas fluorescens WCS365 can improve root colonization of other wild-type Pseudomonas spp. bacteria. Mol. Plant-Microbe Interact. 13:1177-1183.

Downer, J., Faber, B., and Menge, J. A. 2002. Factors affecting root rot control in mulched avocado orchards. Hort. Technol. 12:601-605.

Duffy, B. K., and Defago, G. 1999. Environmental factors modulating antibiotic and siderophore biosynthesis by Pseudomonas fluorescens biocontrol strains. Appl. Environ. Microbiol. 65:2429-2438.

Erwin, D. C., and Ribeiro, O. K. 1996. Phytophthora diseases worldwide. American Phytopathological Society Press, St. Paul, MN, U.S.A

Fiddaman, P. J., and Rossall, S. 1994. Effect of substrate on the production of antifungal volatiles from Bacillus subtilis. J. Appl. Bacteriol. 76:395-405.

Figurski, D. H., and Helinski, D. R. 1979. Replication of an origin-containing derivative of plasmid RK2 dependent on a plasmid function provided by trans. Proc. Natl. Acad. Sci. U.S.A. 76:1648-1652.

Freeman, S., Sztejnberg, A., and Chet, I. 1986. Evaluation of Trichoderma as a biocontrol agent for Rosellinia necatrix. Plant Soil 94:163-170.

Gaffney, T. D., Lam, S. T., Ligon, J., Gates, K., Frazelle, A., Di Maio, J., Hill, S., Goodwin, S., Torkewitz, N., Allshouse, A. M., Kempf, H.-J., and Becker, J. O. 1994. Global regulation of expression of antifungal factors by a Pseudomonas fluorescens biological control strain, Mol. Plant-Microbe Interact. 7:455-463.

Geels, F. P., and Schippers, G. 1983. Selection of antagonistic fluorescent Pseudomonas spp., and their root colonization and persistence following treatment of seed potatoes. Phytopathol. Z 108:193-206.

Gerhardt, P. 1994. Methods for general and molecular bacteriology. American Society for Microbiology Press, Washington, DC.

Greenberger, A., Yogev, A., Katan, J. 1987. Induced suppressiveness in solarized soils. Phytopathology 77:1663-1667.

Howell, C. R., and Stipanovic, R. D. 1979. Control of Rhizoctonia solani on cotton seedlings with Pseudomonas fluorescens and with an antibiotic produced by the bacterium. Phytopathology 69:480-482.

Howell, C. R., and Stipanovic, R. D. 1980. Suppression of Pythium ultimum induced damping off cotton seedlings by Pseudomonas fluorescens and its antibiotic, pyoluteorin. Phytopathology 70:712-715.

Huang, Z., Bonsall, R. F., Mavrodi, D. V., Weller, D. M., and Thomashow, L. S. 2004. Transformation of Pseudomonas fluorescens with genes for biosynthesis of phenazine-1-carboxilic acid improves biocontrol of rhizoctonia root rot and in situ antibiotic production. FEMS (Fed. Eur. Microbiol. Soc.) Microbiol. Ecol. 49:243-251.

Kanda, N., Ishizaki, N., Inoue, N., Oshima, M., and Handa, A. 1975. DB2073, a new alkylresorcinol antibiotic. I. Taxonomy, isolation and characterization. J. Antibiot. (Tokyo) 28:935-942.

Keel, C., Schnider, U., Maurhofer, M., Voisard, C., Laville, J., Burger, U., Wirthner, P., Haas, D., and Defago, G. 1992. Suppression of root diseases by Pseudomonas fluorescens CHA0: Importance of the bacterial secondary metabolite 2,4-diacetylphloroglucinol. Mol. Plant-Microbe Interact. 5:4-13.

King, E. D., Ward, M. K., and Raney, D. E. 1954. Two simple media for the demonstration of pyocyanin and fluorescein. J. Lab. Clin. Med. 44:301-307.

Kitahara, T., and N. Kanda. 1975. DB-2073, a new alkylresorcinol antibiotic. II. The chemical structure of DB-2073. J. Antibiot. (Tokyo) 28:943-946.

Kragelund, L., Christofferson, B., Nybroe, O., de Bruijn, F. J. 1995. Isolation of lux reporter gene fusions in Pseudomonas fluorescens DF57 inducible by nitrogen or phosphorus starvation. FEMS (Fed. Eur. Microbiol. Soc.) Microbiol. Ecol. 17:95-106.

López-Solanilla, E., García-Olmedo, F., and Rodríguez-Palenzuela, P. 1998. Inactivation of the sapA to sapF locus of Erwinia chrysanthemi reveals common features in plant and animal bacterial pathogenesis. Plant Cell 10:917-924.

López-Herrera, C. J., Pérez-Jiménez, R. M., Zea-Bonilla, T., BasalloteUreba, M. J., and Melero-Vara, J. M. 1998. Soil solarization in established avocado trees for control of Dematophora necatrix. Plant Dis. 82:1088-1092.

Lugtenberg, B. J. J., Dekkers, L. C., and Bloemberg, G. V. 2001. Molecular determinants of rhizosphere colonization by Pseudomonas. Annu.
Rev. Phytopathol. 39:461-490.

Lugtenberg, B. J. J., de Weger, L. A., and Schippers, B. 1994. Bacterization to protect seeds and rhizosphere against disease. BCPC Monograph 57:293-302.

Masai, E., Sasaki, M. Minakawa, Y. Abe, T. Sonoki, T. Miyauchi, K. Katayama, Y., and Fukuda, M. 2004. A novel tetrahydrofolate-dependent $O$-demethylase gene is essential for growth of Sphingomonas paucimobilis SYK-6 with syringate. J. Bacteriol. 186:2757-2765.

Murashige, T., and Skoog, F. 1962. A revised medium for rapid growth and bio assays with tobacco tissue cultures. Physiol. Plantarum 15:473-479.

Nowak-Thompson, B., Hammer, P. E., Hill, D. S., Stafford, J., Torkewitz, N., Gaffney, T. D., Lam, S. T., Molnár, I., and Ligon, J. M. 2003. 2,5dialkilresorcinol biosynthesis in Pseudomonas aurantiaca: Novel headto-head condensation of two fatty acid-derived precursors. J. Bacteriol. 185:860-869.

O’Sullivan, D. J., and O'Gara, F. 1992. Traits of fluorescent Pseudomonas spp. involved in suppression of plant root pathogens. Microbiol. Rev. 56:662-676.

Paulitz, T. C. 2000. Population dynamics of biocontrol agents and pathogens in soils and rhizospheres. Eur. J. Plant Pathol. 106:401-413.

Pérez-Jiménez, R. 1997. Podredumbres radiculares del aguacate (Persea americana Mill.) en el Sur de Andalucía. Ph.D. thesis. University of Málaga, Spain

Pieterse, C. M. J., van Wees, S. C. M., Hoffland, E., van Pelt, J. A., and van Loon, L. C. 1996. Systemic resistance in Arabidopsis induced by biocontrol bacteria is independent of salicylic acid accumulation and pathogenesis related gene expression. Plant Cell 8:1225-1237.

Pliego-Alfaro, F., López-Encina, C., and Barceló-Muñoz, A. 1987. Propagation of avocado rootstocks by tissue culture. South African Avocado Growers' Association Yearbook 10:36-39.

Sacherer, P., Défago, G., and Haas, D. 1994. Extracellular protease and phospholipase $\mathrm{C}$ are controlled by the global regulator gene gac $\mathrm{A}$ in the biocontrol strain Pseudomonas fluorescens CHA0. FEMS (Fed. Eur. Microbiol. Soc.) Microbiol. Lett. 116:155-160.

Sankawa, U., Shimada, H., and Yamasaki, K. 1981. Biosynthesis of 2hexil-5-propylresorcinol: Biosynthetic incorporation of deuterium from $\left[2-{ }^{13} \mathrm{C}, 2-{ }^{2} \mathrm{H}_{3}\right]$-acetate. Chem. Pharm. Bull. 29:3601-3605.

Sambrook, J., and D. W. Russell. 2001. Molecular Cloning: A Laboratory Manual. Cold Spring Harbor Laboratory Press, Cold Spring Harbor, NY, U.S.A

Schroth, M. N., and Hancock, J. G. 1982. Disease-suppressive soil and root-colonizing bacteria. Science 216:1376-1381.

Simons, M., van der Bij, A. J., Brand, J., de Weger, L. A., Wijffelman, C. A., and Lugtenberg, B. J. J. 1996. Gnotobiotic system for studying rhizosphere colonization by plant growth-promoting Pseudomonas bacteria. Mol. Plant-Microbe Interact. 9:600-607.

Sokal, R. R., and Rohlf, F. J. 1986. Introducción a la bioestadística. Ed. Reverté S.A., Barcelona, Spain.

Stackebrandt, E., and Goodfellow, M. 1991. Nucleic Acid Techniques In Bacterial Systematics. John Wiley \& Sons, Chichester, NY, U.S.A.

Sztejnberg, A., Freeman, S., Chet, I., and Katan, J. 1987. Control of Rosellinia necatrix in soil and in orchards by solarization and Trichoderma harzianum. Plant Dis. 71:365-369.

Sztejnberg, A., and Madar, Z. 1980. Host range of Dematophora necatrix, the cause of white root rot disease in fruit trees. Plant Dis. 64:662-664.

Sztejnberg, A., Omary, N., and Pinkas, Y. 1983. Control of Rosellinia necatrix by deep placement and hot treatment with methyl bromide. EPPO Bull. 13:483-485.

Teixeira de Sousa, A. J. 1985. Lutte contre Rosellinia necatrix (Harting) Berlese, agent du "pourridié laineux": Sensibilité de quelques espèces végétales et lutte chimique. Eur. J. For. Pathol. 15:323-332.

Thomashow, L. S., and Weller, D. M. 1988. Role of phenazine antibiotic from Pseudomonas fluorescens in biological control of Gaeumannomyces graminis var. tritici. J. Bacteriol. 170:3499-3508.

Voisard, C., Keel, C., Haas, D., and Defago, G. 1989. Cyanide production by Pseudomonas fluorescens helps suppress black root rot of tobacco under gnotobiotic conditions. EMBO (Eur. Mol. Biol. Organ.) J. 8:351-358.

Whistler, C. A., Stockwell, V. O., and Loper, J. E. 2000. Lon protease influences antibiotic production and UV tolerance of Pseudomonas fluorescens Pf-5. Appl. Environ. Microbiol. 66:2718-2725.

Wolk, C. P., Cai, Y., and Panoff, J. M. 1991. Use of a transposon with luciferase as a reporter to identify environmentally responsive genes in a cyanobacterium. Proc. Natl. Acad. Sci. U.S.A. 88:5355-5359.

Yin, B., Scupham, A. J., Menge, J. A., and Borneman, J. 2004. Identifying microorganisms which fill a niche similar to that of the pathogen: A new investigative approach for discovering biological control organisms. Plant Soil 259:19-27. 